Artigo original

Hegemonia - Revista Eletrônica de Relações Internacionais do Centro Universitário Unieuro

ISSN: $1809-1261$

UNIEURO, Brasília, número 11, 2013, pp. 4-35

Recebido em: 11/10/2012

Revisado em: 23/10/2012

Aprovado em: $21 / 2 / 2013$

\title{
BRASIL: A PAZ E AS GUERRAS TRANSNACIONAIS
}

FONSECA, Vicente ${ }^{1}$

Resumo: $O$ presente artigo tem como objetivo principal provar a vocação e o interesse do nosso país em contribuir efetivamente para a manutenção da paz mundial e lutar contra as guerras transnacionais. O papel do Brasil no sistema internacional de manutenção da paz do mundo é analisado, tanto do ponto de vista externo, como interno, onde mostramos a nossa grande luta para solucionarmos os desequilíbrios internos e ao mesmo tempo podermos participar ativamente no cenário internacional. Estudamos os novos horizontes, neste início do século XXI, tendo como parâmetros principais a conjuntura internacional, onde assistimos a volta ao Estado, a mudança de um sistema multipolar para o unipolarismo, as guerras transnacionais, o terrorismo; e um novo sistema de alianças. Finalmente, tentamos provar que a participação do Brasil, no século XXI, será uma das mais importantes, sobretudo quando a humanidade sentir a necessidade de estabelecer novos critérios para sobrevivência, mesmo antes da quebra da atual matriz energética internacional, baseada no uso de combustíveis fósseis

Palavras-Chaves: Paz mundial; multipolarismo; guerras trans nacionais; terrorismo; ordem internacional; humanidade.

Abstract: The main objective was to prove the vocation and the interest of our Country in effectively contributing to the maintenance of the world peace and fight against the transnational wars and terrorism. The

1 Doutor e Mestre em Ciência Política pela Université de Paris 1 - Panthéon Sorbonne. 
Artigo original

Hegemonia - Revista Eletrônica de Relações Internacionais do Centro Universitário Unieuro

ISSN: $1809-1261$

UNIEURO, Brasília, número 11, 2013, pp. 4-35

role of Brazil within the international system of maintenance of peace in the world is exhaustively analyzed from both the external and internal point of view where we expose our great struggle to solve the internal unbalances and, at the same time, how to get an active participation in the international scenario. The new horizons in this beginning of the $21^{\text {st }}$ century having as main parameters the international conjuncture, the returning to the State, the changing of a multipolar system to the unipolarism, the transnational wars, the terrorism and a new alliance system are also part of this study. Finally, we try to prove that Brazil's participation in the $21^{\text {st }}$ century will be among the most important ones, especially when the mankind feel the need to establish new criteria for survival, even before the breaking of the current international energetic matrix, based on the use of fossils fuel.

Keywords: World peace ;multipolarism; transnacionals wars; terrorism; international scenario; mankind.

INTRODUÇÃO

Este ensaio está dirigido para ser um instrumento intelectual visando estimular o estudo sobre o papel e o posicionamento atual e futuro do Brasil, no concerto das nações e os impactos das guerras transnacionais; como elemento desestabilizador da coexistência pacífica no mundo contemporâneo.

Vamos fazer um recorte na história e na política para mostrar a vocação do Brasil em ajudar a construir e consolidar o processo de paz no mundo, sobretudo neste momento de reconfiguração sistêmica do jogo de poder, onde saímos de um bipolarismo; para um multipolarismo 
Artigo original

Hegemonia - Revista Eletrônica de Relações Internacionais do Centro Universitário Unieuro

ISSN: $1809-1261$

UNIEURO, Brasília, número 11, 2013, pp. 4-35

e possivelmente estaremos voltando em médio prazo para um novo bipolarismo, tendo como zona de atrito a guerras transnacionais.

Neste contexto, vamos tomar como base os ataques perpetrados em Nova York e Washington, em 11 de setembro de 2001; o ataque a representação diplomática norte-americana na Líbia, matando o Embaixador Christian Stevens, agora em 2012, que recolocaram a prioridade da análise do terrorismo como catalisador dos arranjos de força na sua função de critério para distinguir amigos de inimigos, tendo como pano de fundo as ideologias religiosas. Isto nos obriga, como estudiosos destes temas, a recuperar as reflexões que historicamente se fizeram sobre o terror e o terrorismo para atualizá-las à luz daquilo que apresentam como um aspecto novo.

Na verdade, o terrorismo não é um fenômeno recente. Ele é tão antigo quanto a guerra, a mesma que acompanha a sociedade desde os seus primórdios. Os Estados, os exércitos, as etnias, os grupos e os homens isoladamente têm empregado o expediente do terrorismo como forma de diminuir a coragem dos seus inimigos para reduzir sua resistência e facilitar a vitória.

Nosso artigo vai tentar mostrar a formação do Brasil e sua vocação para ajudar na construção de um sistema equilibrado de manutenção da paz mundial. 
Artigo original

Hegemonia - Revista Eletrônica de Relações Internacionais do Centro Universitário Unieuro

ISSN: $1809-1261$

UNIEURO, Brasília, número 11, 2013, pp. 4-35

ANÁLISE POLÍTICA

A história política e das relações internacionais do nosso país, mostra claramente a evolução do Estado brasileiro, seus conflitos e seus primeiros esforços para a manutenção da paz, sobretudo com a efetiva participação da nossa delegação chefiada pelo político paraibano, precisamente da cidade de Umbuzeiro, Eptácio Pessoa e os seguintes delegados, Olinto de Magalhães e José de Pandiá Calógeras que adotaram posições de destaque para a criação da Liga das Nações.

Vale salientar que a ideia da criação de um fórum internacional deste porte sempre foi motivo de estudos políticos internacionais ao longo dos séculos, tendo sido também ventilada esta ideia pela Revolução Francesa de 1789, mas só foi teorizada pelo cientista inglês Edward Carr, conhecido como o pai da teoria das relações internacionais, no começo do século $X X$, que também participou da Conferência de Paris.

Outra figura de grande importância é o padre espanhol Francisco Suarez, que lançou a ideia da criação da Liga das Nações. Suarez cresceu e morreu em Portugal em 1618, mas nasceu em Granada em 
Artigo original

Hegemonia - Revista Eletrônica de Relações Internacionais do Centro Universitário Unieuro

ISSN: $1809-1261$

UNIEURO, Brasília, número 11, 2013, pp. 4-35

1548, entrou em 1564 em um noviciado de jesuítas de Monterrey, na

Galícia, ensinou filosofia e teologia. Amigo das soluções médias, foi um dos promotores do congruismo, sistema teológico que tentou conciliar o livre arbítrio do homem com a presença de Deus.

As obras de Suarez: Tratados Metafísicos, Comentários sobre a Suma de Santo Thomás de Aquino, Tratado da Graça de Divina; Tratado das Leis, foram publicadas em Lyon em 1630 e reeditadas em Paris pelo Padre Berton, em 1859.

As suas palavras lançando a grande ideia do congruísmo foram:

"A raça humana, se bem que dividida em povos e reinos diversos, possui não somente a sua unidade específica como também uma certa "unidade moral e quase política", que se encontra nos preceitos naturais de amor e de simpatias recíprocas que se estendem a todos, até aos estrangeiros".

A ideia do governo brasileiro atual é a de tomar a natureza como reservatório dos elementos essenciais à vida e ao processo civilizatório do mundo. Hoje as grandes potenciais, principalmente os Estados Unidos da América do Norte, agem de maneira ao contrário , ao desvalorizar os bens livres e substituí-los por moeda abstrata que deveria simbolizá-los, criando assim um enorme hiato de valor, que leva o planeta a um estado permanente de conflitos. 
Artigo original

Hegemonia - Revista Eletrônica de Relações Internacionais do Centro Universitário Unieuro

ISSN: $1809-1261$

UNIEURO, Brasília, número 11, 2013, pp. 4-35

O Brasil durante a reunião de Cancún em setembro de 2003, liderou um grupo de 20 países em desenvolvimento, com vistas a dar continuidade a construção de um sistema que obtenha uma estabilidade nas relações entre os povos, com o fito de superar as grandes barreiras existentes , mas também começar a construir um modelo de entendimento novo, para superamos um possível colapso da economia mundial.

Na última parte deste trabalho vamos sugerir a criação de novas estratégias políticas de relações internacionais, tendo como ponto focal, principalmente a Alemanha, a França, a Índia, a China, a Rússia e o Japão, tendo como base a eliminação gradual do uso de combustíveis fósseis, substituindo-o pelo uso da energia limpa, onde naturalmente o Brasil seria o grande provedor. Desta forma, a nossa tese tem finalmente como objeto de sustentação a proposta da montagem de uma nova configuração do concerto das nações, respaldada na manutenção da paz através do uso adequado dos bens naturais, que temos convicção que poderá alcançar um patamar de estabilidade e harmonia, sem que haja necessidade do uso da força militar ou econômica, que já provaram durante toda a existência da humanidade que não conseguem trazer a tão esperada paz eterna, sempre almejada pelos seres humanos deste planeta. 
Artigo original

Hegemonia - Revista Eletrônica de Relações Internacionais do Centro Universitário Unieuro

ISSN: $1809-1261$

UNIEURO, Brasília, número 11, 2013, pp. 4-35

\section{QUAL É O SIGINIFICADO DE GUERRAS TRANSNACIONAIS?}

Os ataques perpetrados em Nova York e Washington, em 11 de setembro, recolocaram a prioridade da análise do fenômeno das relações de força na agenda dos estudos das Relações Internacionais e o terrorismo no centro da mesma, como catalisador dos arranjos de força na sua função de critério para distinguir amigos de inimigos ${ }^{2}$. Isto nos obriga, como estudiosos destes temas, a recuperar as reflexões que historicamente se fizeram sobre o terror e o terrorismo para atualiza-las à luz daquilo que apresentam como um aspecto novo.

Na verdade, o terrorismo não é um fenômeno recente. Ele é tão antigo quanto a guerra, a mesma que acompanha a sociedade desde os seus primórdios. Os Estados, os exércitos, as etnias, os grupos e os homens isoladamente têm empregado o expediente do terrorismo como forma de diminuir a coragem dos seus inimigos para reduzir sua resistência e facilitar a vitória. De assassinatos até etnocídios, passando por genocídios com o único objetivo de infundir o terror, a humanidade,

2 - Para Charles Zorgbibe; a possibilidade de realizar esta distinção entre amigos e inimigos constitui a essência que define o âmbito específico do político. 
Artigo original

Hegemonia - Revista Eletrônica de Relações Internacionais do Centro Universitário Unieuro

ISSN: $1809-1261$

UNIEURO, Brasília, número 11, 2013, pp. 4-35

em todos os rincões do globo, tem conhecido desde sempre este fenômeno. A tétrica característica que recobre com um manto de novidade este velho flagelo é sua atual e crescente internacionalização.

A característica internacional do terrorismo pode ser nova, mas não surpreendente. Com efeito, num mundo cuja novidade consiste na hegemonia incontestada de uma superpotência com interesses globais, onde a realização desses interesses dificilmente se completa sem ferir outros interesses, a colheita de ódio torna-se inevitável. Quando nenhuma ação diplomática é eficiente para defender interesses postergados; quando nenhum organismo internacional é suficientemente forte para distribuir justiça entre interesses afetados; quando nenhuma forma convencional de manifestação da violência é eficaz para defender tais interesses, fica aberta a porta para que aquele ódio se manifeste de maneira incontrolável e muitas vezes irracionalmente com relação aos seus objetivos.

Diferentemente do que anunciaram alguns observadores, a guerra contra o Iraque não foi a primeira de um novo tipo, mas a última das clássicas. Nela ficou claro, como observa Charles Zorgbibe, que qualquer exército convencional é impotente ante a manifestação pretoriana da superpotência. Diante desta constatação, qualquer pretensão conta com 
Artigo original

Hegemonia - Revista Eletrônica de Relações Internacionais do Centro Universitário Unieuro

ISSN: $1809-1261$

UNIEURO, Brasília, número 11, 2013, pp. 4-35

apenas dois caminhos de igual possibilidade: o poder igualitário do átomo, demasiado longe para os países pobres, ou o recurso à guerra assimétrica: a guerrilha e o terrorismo. Estas formas, especialmente o terrorismo pela sua simplicidade operativa, seu baixo custo, seu efeito devastador e a facilidade de transnacionalizá-lo, são as alternativas de manifestação do ódio ante o atropelo dos seus interesses. Com relação à internacionalização do terror: ante uma hegemonia planetária com interesses globais o terreno de operações torna-se também global. E assim, "Afastamo-nos das guerras convencionais, limitadas aos especialistas, que podiam constituir uma forma de continuação da política por outros meios; estamos na era da guerra de todos contra todos"3

Os atentados do 11 de setembro provocaram uma nova reordenação mundial em função de um "terrorismo" não definido ou, o que é pior, mal definido. O uso extensivo que o Departamento de Estado Norte Americano vem fazendo do conceito de "terrorismo internacional" não leva em conta uma distinção que acadêmica e politicamente deve ser feita entre os critérios especificamente definicionais e os pragmáticopolíticos. Por exemplo, houve outros notórios incidentes no Cone Sul,

3 .- Eric de La Maisonneuve, La metamorfosis de la violencia. Ensayo sobre la guerra moderna. Buenos Aires, Grupo Editor Latinoamericano, 1998, pp 175-222. A citação é da pag. 184. 
Artigo original

Hegemonia - Revista Eletrônica de Relações Internacionais do Centro Universitário Unieuro

ISSN: $1809-1261$

UNIEURO, Brasília, número 11, 2013, pp. 4-35

como o caso do ataque à Embaixada de Israel na Argentina e, posteriormente, a bomba que destruiu a Asociación Mutual Israelita Argentina (AMIA), ambos de importante repercussão mundial, mas que não foram considerados casos de "terrorismo internacional". Não se solicitou, entretanto, como depois do 11 de setembro, um apoio internacional à luta contra o terrorismo, embora talvez fosse da mesma origem. Não foram investigados depósitos bancários nem se recorreu a uma internacional de inteligência. Não houve solidariedade internacional, o perigo parecia demasiado longe como para intimidar a Potência que ainda se percebia invulnerável

Mas, desta vez, quando o impacto foi no coração do sistema financeiro internacional e no centro do sistema nervoso da pletora que o defende, quando ficou claro que não existe escudo nuclear suficiente nem Superpotência invulnerável ao terror, que a potencia que emergiu hegemônica do confronto mundial de meio século pode ser alvo de um ataque terrorista, a comunidade internacional reúne-se num ato condenatório e decide combater solidariamente na "guerra" que os Estados Unidos empreendam contra o "terrorismo" independentemente do peso semântico que oculte este conceito. 
Artigo original

Hegemonia - Revista Eletrônica de Relações Internacionais do Centro Universitário Unieuro

ISSN: $1809-1261$

UNIEURO, Brasília, número 11, 2013, pp. 4-35

O terrorismo pode ser combatido. Mas, precisamente por isso, devem ficar perfeitamente claros os critérios para definir o que se entende por "terrorismo", assim como devem ser explicitados os critérios de aplicação dessa definição e discutidos os meios mais eficazes para levar a cabo esse combate.

Há duas formas de definir um fenômeno, aquela que define intencionalmente, por um atributo específico do definido, como o aristotélico "gênero próximo e diferencia específica", ou extencionalmente, isto é, pela numeração extensiva dos elementos que fazem parte do conjunto definido. A precaução sobre os critérios empregados para definir "terrorismo" fica dramaticamente justificada quando aquela potencia hegemônica, por uma definição puramente extencional de terrorismo, publica suas famosas "listas" de grupos que ela considera "terroristas", grupos estes contra os quais os governos solidários no combate ao terrorismo poderão, e muitas vezes deverão, ver-se compelidos a guerrear.

A importância destas definições reside no fato que elas delimitam a frente de combate internacional ao terrorismo e essas 
Artigo original

Hegemonia - Revista Eletrônica de Relações Internacionais do Centro Universitário Unieuro

ISSN: $1809-1261$

UNIEURO, Brasília, número 11, 2013, pp. 4-35

listas, hoje definidas arbitrariamente, provocam pânico ${ }^{4}$ nos povos e confusão nas políticas de defesa latino-americanas. Nessas listas, que por obedecer a critérios extencionais em lugar de definir o terrorismo intencionalmente estão sujeitas a caprichos políticos, aparecem grupos guerrilheiros que disputam o monopólio da violência em países da região, como por exemplo as FARC, que combatem na fronteira norte do Brasil. Pode-se argumentar que as FARC talvez pratiquem atos terroristas, ainda assim, é discutível que essas ações táticas os incluam na definição de terroristas. Táticas terroristas são frequentemente usadas, em muitos casos por exércitos regulares, inclusive o da Colômbia e o dos Estados Unidos, por exemplo, mas esses atos, por si sós, não os tornam terroristas, como não torna terrorista a George Bush apenas sua frase terrorista "quem não estiver do lado dos Estados Unidos estará contra e será combatido".

Acredito que a gravidade da situação internacional, da necessidade de combater consciente e eficazmente $o$ flagelo do terrorismo, das exigências éticas e políticas de discutir critérios claros para definir esse fenômeno, justificam um pequeno vôo teórico em torno

4 - Destaquei a face terrorista desta guerra contra o terrorismo em "Até tu Arafat?", Jornal do Brasil, RJ, 14-09-01. 
Artigo original

Hegemonia - Revista Eletrônica de Relações Internacionais do Centro Universitário Unieuro

ISSN: $1809-1261$

UNIEURO, Brasília, número 11, 2013, pp. 4-35

do conceito de "terrorismo" tentando tornar mais nítidos os seus contornos e firme o núcleo duro da sua definição.

\section{AS DIFERENTES FACES DO TERRORISMO}

A visão do terrorismo em função da vítima e mais precisamente, pelo peculiar critério com que o terrorista seleciona a sua vítima, será mostrado a seguir. A constatação da falta de conceitualização adequada sobre "terrorismo" com que a mídia mundial cobria os acontecimentos, assim como a confusão e pânico que esta inadequação provocava na opinião pública em geral, me convenceram a retomar aquela conceitualização, aprofundá-la e melhorá-la

O terrorismo é uma forma de violência cujo efeito realiza-se no âmbito psicológico do individuo ${ }^{5}$ Seu objetivo é produzir uma reação psicológica e, portanto, íntima reação no individuo: o terror, isto é, um pavor incontrolável. O terrorismo é um ato de violência que provoca uma ação social, uma reação de força contraria, isto é, constitui uma relação de força. Enquanto relação de força, pode ser analisado nos três níveis nos quais normalmente se manifesta, tratando de identificar em

5 - Ver de Reinares, Fernando: Terrorismo y Antiterrorismo, Buenos Aires, Paidos, 1998 e deWardlaw, Grant: Political Terrorism, Cambridge, cambridge university Press, 1984, especialmente o Cap. IV. 
Artigo original

Hegemonia - Revista Eletrônica de Relações Internacionais do Centro Universitário Unieuro

ISSN: $1809-1261$

UNIEURO, Brasília, número 11, 2013, pp. 4-35

cada um deles os objetivos aos quais o terrorismo se devota: Por exemplo no:

- Nível Tático: É o nível mais visível de toda relação de força, é a sua expressão direta e concreta, a aplicação direta da força, o combate, a "gramática da guerra" como diria Clausewitz. Neste nível, o objetivo visado pelo terrorismo é provocar o maior dano possível. Matar, mutilar, com a maior visibilidade e crueldade possíveis, expressado com os requintes de qualquer meio. Desde facas até bombas passando por todos os tipos de armas, convencionais ou não, que são empregadas para mostrar que não há limite para o seu acionamento. O emprego epistolar da bactéria antrax nos Estados Unidos nos dias que seguiram aos tentados de 11 de setembro, ou o gás sarín, utilizado no metrô de Tóquio, são apenas exemplos de que até armamento químico, biológico e eventualmente nuclear, se caísse nas suas mãos, poderia fazer parte do arsenal do terror para provocar o maior dano possível e obter a maior visibilidade.

- Nível Estratégico: O objetivo estratégico de todo exercício de força é outorgar a vitória na guerra, com ela ou com a ameaça da sua aplicação. O que se espera neste nível é desobstruir de impedimentos o caminho para a execução dos fins pelos quais a política estabeleceu 
Artigo original

Hegemonia - Revista Eletrônica de Relações Internacionais do Centro Universitário Unieuro

ISSN: $1809-1261$

UNIEURO, Brasília, número 11, 2013, pp. 4-35

essa relação de força; dito de outra maneira, retirar a capacidade de combate e a vontade de resistência do inimigo. No caso do terrorismo, o objetivo estratégico é sempre provocar terror, aquele pavor incontrolável que produz nas pessoas a sensação irresistível de ser vulnerável e de estar exposto à violência homicida. O terrorismo manifesta no nível estratégico uma especificidade que o torna singular: diferentemente de outras ações de violência política, esta forma de violência não emprega os seus meios táticos para lograr a vitória na guerra nem a tomada do poder, mas, provocar um pânico incontrolável na população ou em uma parte definida desta. Portanto, o objetivo estratégico do terrorismo, que o distingue de qualquer outra relação de força e o define, é provocar terror.

- Nível Político: Neste nível realizam-se os objetivos pelos quais uma guerra leva-se a cabo. É a política quem escolhe o inimigo; define a lógica da guerra e as formas de retorno à paz; os acordos e os custos que serão impostos ao vencido; a imposição da vontade para a qual os meios diplomáticos resultaram impotentes tornando a guerra viável. No caso do terrorismo não há imposição da vontade, mas apenas a fratura da vontade do inimigo. Como não objetiva a tomada do poder (nenhum grupo terrorista deseja o poder político, mas 
Artigo original

Hegemonia - Revista Eletrônica de Relações Internacionais do Centro Universitário Unieuro

ISSN: $1809-1261$

UNIEURO, Brasília, número 11, 2013, pp. 4-35

apenas sua destruição) não pode pretender impor a sua vontade, pelo menos não a sua vontade positiva, mas a sua vontade negativa, a desestabilização do inimigo, o desmembramento do tecido social, a falência do Estado. Nem sequer todos os grupos terroristas têm ou perseguem fundamentos políticos, o grupo japonês acima referido, com seu objetivo especificamente milenarista, é um exemplo. Portanto, é difícil definir o terrorismo pela sua finalidade política, como a qualquer outro tipo de relação de força, inclusive a guerra. Raymond Aron dizia que uma guerra se define pela caracterização política dos beligerantes e pelas formas de retorno à paz. No caso do terrorismo, esta definição é inaplicável: é difícil caracterizar politicamente aos terroristas (que nem beligerantes são, em sentido estrito) e não existe a possibilidade de se pensar no retorno à paz.

Em função desta tripartição do fenômeno do terrorismo, podemos pensar na diferente natureza que a vítima deste tipo de acionar assume para cada um dos três níveis de análise. Assim, para o nível tático, estratégico e político poderemos encontrar:

1. A vitima tática, é a vitima direta, o morto, o esfaqueado, o assassinado, o mutilado, o explodido, o sequestrado, enfim, 
Artigo original

Hegemonia - Revista Eletrônica de Relações Internacionais do Centro Universitário Unieuro

ISSN: $1809-1261$

UNIEURO, Brasília, número 11, 2013, pp. 4-35

aquele que sofre na sua própria pessoa a violência do atentado e deixa sua vida no mesmo ou por ele é diretamente afetado.

2. A vitima estratégica são todos aqueles que sobrevivem ao atentado, mas que se encontram de alguma maneira dentro do grupo de risco dos vitimados. Eles não são atingidos diretamente pelo atentado, mas, sabendo-se vulneráveis e sujeitos à possibilidade de serem a próxima vitima tática, são presas do pânico. Esta é a vitima visada pelo terrorista: é aquela que não morre, a que permanece viva e aterrada.

3. Embora possa não ter objetivos políticos, o terrorismo pode e normalmente tem uma vitima política: é o Estado, aquela estrutura que deveria garantir a vida dos seus cidadãos, para o qual recolhe pesados tributos com o argumento e a justificativa de que com a arrecadação poderá montar uma maquinaria bélica e de segurança que capaz de assegurar a vida, a propriedade e a tranquilidade de todos os cidadãos.

Note-se que a vitima preferencial do terrorismo, a vitima estratégica, não é o morto, a vítima tática. Inegavelmente o terrorista procurará provocar o maior dano possível e portanto tentará executar a 
Artigo original

Hegemonia - Revista Eletrônica de Relações Internacionais do Centro Universitário Unieuro

ISSN: $1809-1261$

UNIEURO, Brasília, número 11, 2013, pp. 4-35

maior quantidade possível de vitimas no nível tático da operação. Porém, se o objetivo estratégico é provocar o terror, um pânico incontrolável, obviamente a vitima estratégica não pode ser nunca a vitima tática, aquela que perde a sua vida no atentado, por uma questão eminentemente ontológica: os mortos não temem. Com efeito, a vitima objetivada estrategicamente pelo terrorismo não é o morto que tomba no atentado, pois ele já não temerá por nada, mas todos aqueles que ficam vivos e conscientes do cálculo de probabilidades que os coloca aleatória ou seletivamente na conta dos que podem ser a próxima vítima tática. O fundamento do terror não é a morte, mas a insegurança que provoca a certeza da sua vulnerabilidade ante o acionar do terrorista. O fundamento do terror é o sentimento inequívoco de desamparo ante a vontade do terrorista.

\section{COMO SE CLASSIFICA O TERRORISMO}

Existem vários tipos de terrorismo obedecendo a diferentes critérios classificatórios. Em função do sujeito do terrorismo, por exemplo, pode-se tipificá-lo a partir da pergunta "quem é o terrorista?" Nesse caso as ações podem ser individuais, quando o atentado é realizado por um indivíduo isolado e sem ligação com nenhuma 
Artigo original

Hegemonia - Revista Eletrônica de Relações Internacionais do Centro Universitário Unieuro

ISSN: $1809-1261$

UNIEURO, Brasília, número 11, 2013, pp. 4-35

organização; grupais, quando a autoria do atentado é atribuída a organizações que podem ser políticas, religiosas, étnicas, etc.; finalmente estatais, quando na sua origem e como seu autor material se encontra o próprio Estado. Conforme o âmbito no qual o terrorismo espalhe o terror, pode se falar de terrorismo Nacional (seja este terrorismo de Estado ou "contra Estado"), quando realizado no âmbito do próprio Estado, de Internacional, quando abrange um contexto político internacional, como no caso das guerras de libertação contra as formas de ocupação do inimigo ${ }^{6}$, ou Transnacional, quando mobilizando recursos humanos e materiais, os grupos terroristas atuam em países alheios aos de sua população de origem7.

Pela modalidade do atentado, pode-se distinguir o terrorismo sexual, psicológico, econômico, militar, etc. Pela consideração dos meios, o terrorismo pode ser perpetrado com qualquer tipo de armas, desde as armas brancas, como nos simbólicos degolamentos na Argélia, até bombas de diferentes potências de explosão. Além disso, com o atentado no metrô de Tóquio e o antrax nos Estados Unidos, ficou claro que nem as armas químicas nem as biológicas estão excluídas nas ações

6 .- Para uma visão mais pormenorizada desta classificação ver de Luigi Bonanate o verbete "Terrorismo Político" in Bobbio N. et alli: Dicionário de Política. Brasilia, ed. UnB, 1986.

7 - Ver de REINARES, Fernando: Terrorismo y Antiterrorismo, Ed. Paidós, Barcelona, 1998, especialmente o capítulo 5 "Terrorismo en la sociedad internacional". 
Artigo original

Hegemonia - Revista Eletrônica de Relações Internacionais do Centro Universitário Unieuro

ISSN: $1809-1261$

UNIEURO, Brasília, número 11, 2013, pp. 4-35

do terrorismo, e, seguindo esta lógica, podemos concluir que também armas atômicas possam fazer parte do arsenal do terror ${ }^{8}$, isto é, armas de destruição em massa (ADM) em mãos do terrorismo, inclusive na sua forma transnacional. ${ }^{9}$

Em função dos objetivos visados, ordenados pela pergunta "para quê?", o terrorismo pode ser patológico, quando não há um objetivo claro, mas o motivo da ação é de ordem psicopatológica, como na maioria dos atentados individuais; religioso, quando o objetivo é aniquilar um grupo religioso ou provocar a adesão religiosa através do medo; econômico, quando o efeito procurado é nessa área, como no caso do terrorismo contra os turistas, em países onde o turismo é a principal fonte de rendas; e político, como quando o objetivo final é a desestabilização do regime. Na verdade, é muito difícil manter esta

8 .- Já foram desmantelados vários intentos de contrabandear material nuclear, em pequenas doses, para a Europa aparentemente vindos da ex-URSS. Em maio de 1992 já advertíamos para esta possibilidade: "O gelo da guerra fria derreteu e sua água radioativa penetrou a porosidade ideológica do mundo (...) O controle nuclear do Leste, caraterizado pela "racionalidade" burocrática, hoje se dilui em vários gatilhos nas mão de líderes tão populistas quanto imprevisíveis" in "A nova (des)ordem mundial", O Estado de S. Paulo, 19-05-92, p. 2. As armas nucleares e biológicas já estão ao alcance dos grupos terroristas, nada impedirá, chegado o caso, que estes grupos as usem. O exemplo do metrô de Tóquio e também o do prédio de Ocklahoma são a constatação de que o terrorismo não tem limites éticos para atingir seus objetivos.

9 .- Ver sobre este aspecto de HOFFMAN, Bruce: A mano amada. História del terrorismo, Madrid, Ed. Espasa Calpe, 1999, especialmente o capítulo 7: "El terrorismo hoy y mañana". 
Artigo original

Hegemonia - Revista Eletrônica de Relações Internacionais do Centro Universitário Unieuro

ISSN: $1809-1261$

UNIEURO, Brasília, número 11, 2013, pp. 4-35

distinção na prática, onde normalmente a explicação responde a uma combinação variável de todos estes aspetos.

Para os objetivos deste trabalho interessa um critério classificatório baseado na seleção da vítima, conforme o terrorista com ela procure intencionalmente precisão identificatória ou não. Em função deste critério distinguem-se dois tipos de terrorismo: o discriminado ou sistemático e o indiscriminado ou aleatório.

a.- Terrorismo sistemático ou discriminatório

O terrorismo sistemático ou discriminatório é aquele que escolhe suas vítimas por alguma característica identificatória, seja esta a religião, a profissão, a cor, a etnia, a classe social, etc. Atentados terroristas com esta característica são os cometidos pelo movimento separatista basco (ETA) contra os militares de alta patente, especialmente comprometidos com a repressão e a tortura; pelo Exército Republicano Irlandês (IRA), contra os soldados do exército inglês ou militantes protestantes; pelos argelinos pertencentes ao braço armado da Frente Islâmica de Salvação (FIS) especialmente contra jornalistas e formadores de opinião; pelos comandos islâmicos egípcios, 
Artigo original

Hegemonia - Revista Eletrônica de Relações Internacionais do Centro Universitário Unieuro

ISSN: $1809-1261$

UNIEURO, Brasília, número 11, 2013, pp. 4-35

contra turistas, visando a principal atividade econômica do Egito; pelos comandos palestinos da Hamas, contra postos militares israelitas; pelos ataques da aviação israelita sobre acampamentos palestinos; pela guerrilha colombiana, contra companhias petroleiras estrangeiras. Este tipo de ação terrorista baseia sua eficácia na correta precisão da identificação da vítima, pois é a partir dessa identificação que os campos da amizade e da inimizade assumem seus contornos políticos com maior nitidez, obrigando à sociedade a tomar partido por um ou outro dos campos.

b - Terrorismo indiscriminado ou aleatório

O terrorismo é aleatório ou indiscriminado quando sua vítima não é definida nem obedece a qualquer seleção sistemática ou política, procurando deliberada e indiscriminadamente vitimar inocentes, em grande número e com a maior diferenciação social possível. O atentado terrorista ideal deste grupo mata homens e mulheres, velhos, jovens e crianças, brancos e negros, militares, sacerdotes, pessoas comuns: não há "grupo de risco", qualquer um pode ser a próxima vítima. Não há atividade, idade, profissão, credo, 
Artigo original

Hegemonia - Revista Eletrônica de Relações Internacionais do Centro Universitário Unieuro

ISSN: $1809-1261$

UNIEURO, Brasília, número 11, 2013, pp. 4-35

cor, ideologia que esteja isento da possibilidade de ser o alvo do atentado.

A universalidade da vítima é a característica principal do terrorismo aleatório, outra é a espetaculosidade do atentado. O momento escolhido é normalmente a plena luz do dia e quando o movimento de pessoas é maior. O lugar às vezes é representativo da ordem social imperante, como tribunais, supermercados, lojas, prédios onde funcionam repartições públicas, meios de transporte coletivos (como o metrô de Tóquio), enfim, lugares de grande concentração ou circulação de pessoas. A morte de crianças, como no atentado no edifício de Oklahoma onde funcionava uma creche, permite mostrar que não há lugar para a piedade, ele é inclemente e precisa manifestá-lo. Seu objetivo é criar um terror incontrolável e generalizado. O cidadão vê em qualquer outro o possível terrorista inimigo. Quando o terrorismo aleatório é eficaz, todo mundo é suspeito, e, como não há identificação política nem ideológica, sua repressão é muito difícil.

O efeito principal deste tipo de terrorismo é a sensação no cidadão de abandono por parte Estado, que ele nada pode fazer para se defender, que não controla a situação, é o que chamamos de desamparo 
Artigo original

Hegemonia - Revista Eletrônica de Relações Internacionais do Centro Universitário Unieuro

ISSN: $1809-1261$

UNIEURO, Brasília, número 11, 2013, pp. 4-35

aprendido $^{10}$. O cidadão sente-se desprotegido e vulnerável ao ataque imprevisível e indiscriminado do terrorismo. Ele sente que aquele Estado, com todas suas estruturas repressivas e preventivas, é absolutamente impotente para protegê-lo. Se o soberano, que é o depositário de todas as vontades e todas as forças, não pode cumprir a única contrapartida que o contrato social dele exige, a saber, a proteção da vida do cidadão, então o Estado perde o elemento de coesão e o tecido social se abre até deixar o cidadão sozinho e aterrorizado. 0 terrorismo não tem como objetivo direto a tomada do poder, nem poderia tê-lo. Seu objetivo direto é a desestabilização do regime vigente através do terror induzido na população. Por isso, quanto mais irracional e aleatório seja seu acionamento, mais eficiente será. Este tipo de terrorismo, diferentemente do sistemático, não identifica um inimigo,

10 .- Tomamos esta expressão de um modelo animal usado para estudar doenças mentais, especialmente a depressão. O modelo é construído a partir da sujeição do animal à técnica do choque incontrolável, isto é, à aplicação de choques elétricos de intensidade e freqüência variáveis, mas inescapáveis. Depois de se debater por algum tempo e procurar a fuga por todos os meios, o animal desiste da fuga, aprendendo que qualquer intento é inútil. Esse é o momento em que o animal aprende que está desamparado, constituindo-se no modelo de depressão. O notável é que, a partir desse momento, o animal não procurará a fuga inclusive em situações em que esta seja possível. Veja-se entre outros de M.S. Faria and N.A. Teixeira, "Reversal of learned helplessness by chronic lithium treatment at a prophylactic level" in Brasilian Journal, 26: 1201-1212 (1993). No caso que estamos analisando, o terrorismo funcionaria como os choques elétricos, seus atentados são aleatórios, de intensidade variável e de frequência incerta; como o Estado não tem condições de garantir a segurança do cidadão, para este a situação apresenta-se como "inescapável". Como o cidadão não pode fazer nada para se salvar do atentado, para garantir sua exclusão da possibilidade de ser a próxima vítima, ele cai em desamparo. 
Artigo original

Hegemonia - Revista Eletrônica de Relações Internacionais do Centro Universitário Unieuro

ISSN: $1809-1261$

UNIEURO, Brasília, número 11, 2013, pp. 4-35

não define âmbitos de inimizade, não define frentes de combate, apenas provoca uma comoção social desintegradora: o espanto.

\section{O 11 DE SETEMBRO}

Com estes mínimos detalhes técnico conceituais podem ser analisados os atentados terroristas perpetrados nos Estados Unidos arrepiando a epiderme das relações de força que caracteriza o mundo. Aqueles acontecimentos colocaram todos os cidadãos norte-americanos na situação de desamparo descrita, isto é, ficaram surpresos, atônitos, sentindo pela primeira vez na própria pele a vertiginosa sensação da vulnerabilidade. No seu próprio país perceberam o seu Estado, o mais poderoso do mundo, impotente para protegê-los desse terrível perigo difuso e global, sem rosto, sem bandeira, sem frente de combate, sem clemência, sem ostentação. No primeiro momento o ataque alcançou seu objetivo, substituiu os Estados Unidos na mais profunda soçobra e assombro e aos seus cidadãos no desamparo. $O$ ataque inscreve-se no tipo que chamamos "terrorismo aleatório". Procurou-se deliberadamente a maior quantidade possível de vitimas táticas para que nenhum cidadão norte-americano possa se sentir seguro. Todo norte-americano 
Artigo original

Hegemonia - Revista Eletrônica de Relações Internacionais do Centro Universitário Unieuro

ISSN: $1809-1261$

UNIEURO, Brasília, número 11, 2013, pp. 4-35

sentiu-se incluído no "grupo de risco". A vitima tática, o morto, o mutilado, não teve qualquer sentido estratégico. A vitima estratégica não são os quatro ou cinco mil mortos no atentado, mas os restantes milhões de norte-americanos que ficaram vivos e sujeitos ao terror.

O desamparo padecido pelo cidadão norte-americano afrouxou o tecido social. Ele percebe que o Estado, aquele que possui o exército mais poderoso do mundo, não pode garantir sua vida na sua própria casa, sente-se desamparado e o tecido social desintegra-se corroendo a legitimidade do poder. Assim é como o terrorismo atinge o seu objetivo político, que não é a tomada do poder, mas simplesmente desestabilizálo. A vítima política do atentado é o Estado norte-americano. Daí o grito terrorista do presidente norte-americano George Bush convocando à "guerra contra o terrorismo" e "aquele país que não se comprometa com essa guerra será considerado inimigo e combatido até a morte". O grito de guerra do Presidente Bush tinha naquele momento um duplo sentido: por um lado, manifestar que ainda havia um Estado norteamericano e que esse Estado chegaria às últimas consequências, isto é, à guerra, para proteger ao seu cidadão de qualquer ameaça; por outro lado, insuflar a confiança no cidadão que sua única proteção é sob amparo desse Estado. Assim, com esta dupla mensagem, o presidente 
Artigo original

Hegemonia - Revista Eletrônica de Relações Internacionais do Centro Universitário Unieuro

ISSN: $1809-1261$

UNIEURO, Brasília, número 11, 2013, pp. 4-35

procurou e em alguma medida conseguiu fechar novamente o tecido social, elevou o espírito do povo norte-americano devolvendo-lhe a esperança. Com estes resultados, logrou o objetivo político desse grito de guerra: recuperar a tensão social e o moral do povo.

O combate ao terrorismo é possível. Negar essa possibilidade é uma declaração de impotência estrategicamente inaceitável. Mas a guerra não é a forma adequada nem o meio militar eficaz para lograr esse objetivo. Há formas políticas de diminuir as tensões e ódios, de antecipar e resolver os conflitos; há meios de inteligência policial que podem auxiliar no desmonte dos grupos terroristas e dissuadi-los da sua intenção. Quatro dias antes dos atentados, numa apresentação realizada em Washington ${ }^{11}$, premonitoriamente defendia que o governo de um país que pretenda e de fato exerça liderança mundial, como o dos Estados Unidos, não podia rasgar, em menos de duas semanas, sete tratados internacionais referidos à segurança de todos os habitantes da terra, como, por exemplo, sobre pequenas armas, sobre controle de armas químicas, das biológicas e das nucleares, sobre o controle de emissão de poluentes, etc. Defendia que uma potência líder

\footnotetext{
11 No encontro da LASA acontecido em Washington na semana anterior aos atentatos, no XXIII International Congress do Latim American Studies Associations, LASA2001, Washington, USA, 06-09-01.
} 
Artigo original

Hegemonia - Revista Eletrônica de Relações Internacionais do Centro Universitário Unieuro

ISSN: $1809-1261$

UNIEURO, Brasília, número 11, 2013, pp. 4-35

não podia ficar de costas aos muitos conflitos do mundo que colocam em risco a segurança humana e que poderiam ser politicamente resolvidos.

CONCLUSÕES

Condenado o atentado e lamentados os mortos, pode-se aproveitar a oportunidade para refletir sobre o fenômeno do terrorismo, sua natureza, suas causas e as formas mas eficientes para combatê-lo e reprimi-lo. Esta poderia ser uma tarefa permanente da comunidade internacional, pois a natureza internacional do terrorismo exige uma prevenção e repressão também internacional. Mas, por outra parte, é urgente a adoção de uma definição intencional, clara e internacionalmente unívoca do fenômeno que impeça a aplicação caprichosa e arbitrariamente política de definições extensionais, formalizadas em "listas" que, como um "ranking" do terrorismo, imponha-se ao mundo exigindo, contra os que nela constem, uma atitude belicosa.

Muitos dos grupos listados pelo governo norte-americano talvez sejam terroristas, mas não o saberemos nem teremos condições de 
Artigo original

Hegemonia - Revista Eletrônica de Relações Internacionais do Centro Universitário Unieuro

ISSN: $1809-1261$

UNIEURO, Brasília, número 11, 2013, pp. 4-35

discuti-lo sem uma ferramenta conceitual adequada, isto é, uma definição intensiva baseada nas características específicas do fenômeno. Acredito ter apontado neste trabalho algumas notas que podem iluminar a procura de uma definição consistente. Mais que se tornar uma definição universalmente aceita, com ela proponho uma discussão do terrorismo sobre bases objetivas. Pode ser entendido como um chamado ao debate, a uma discussão impostergável sobre a sua pertinência e utilidade para definir quem está por detrás das "novas ameaças", se um inimigo ou um criminoso e qual é a melhor maneira de combatê-lo.

Desejo fechar este trabalho chamando a atenção para o crítico momento pelo qual está passando a América Latina. Numa conjuntura na que a crise está acabando com as economias nacionais sem dar respiro aos impotentes e, em muitos casos corruptos governos, em que as desigualdades sociais crescem aceleradamente e as iniquidades dominam o panorama continental, a estabilidade regional pende do delgado fio da manobra. Nessa situação, assumir guerras de terceiros países pode provocar uma desestabilização generalizada com consequências imprevisíveis para a região. Definir politicamente o inimigo é prerrogativa específica e definidora da soberania. Sem definições claras sobre terrorismo, terrorismo internacional, narco terrorismo, narcoguerrilha, crime organizado, etc., correremos o risco 
Artigo original

Hegemonia - Revista Eletrônica de Relações Internacionais do Centro Universitário Unieuro

ISSN: $1809-1261$

UNIEURO, Brasília, número 11, 2013, pp. 4-35

de perder aquela prerrogativa e, entrando numa guerra que não nos pertence e por questões que nossa legislação considera transgressões ou crimes, transformar a América Latina num horrendo campo de batalha onde a vitória é incerta e apenas ganham os que sempre lucraram com as guerras e por isso as promovem. Discutamos agora, enquanto a tênue paz o permita, sobriamente, com a seriedade e o rigor que tema nos impõe, "sine ira et studio" como exigia Max Weber das reflexões científicas, as definições sobre os quais posteriormente os governantes terão que se posicionar, inclusive até para declarar a guerra chegado o caso, mas tendo a certeza da univocidade dos conceitos que estão em pauta. Discutamos agora, na serenidade da ciência, sobre o que não poderemos duvidar no campo de batalha.

\section{BIBLIOGRAFIA}

ABREU, Antônio Moreira de. A Liga das Nações. Rio de Janeiro: Papelaria Brasil, 1919.

ALBAGLI, Sarita (1999), "Novos Espaços de Regulação na Era da informação". In: LASTRES, Helena e ALBAGLI, Sarita: Informação e Globalização na Era do Conhecimento. Pp: 290:313. São Paulo: Campus. 
Artigo original

Hegemonia - Revista Eletrônica de Relações Internacionais do Centro Universitário Unieuro

ISSN: $1809-1261$

UNIEURO, Brasília, número 11, 2013, pp. 4-35

ALBRECHT-CARRIÉ, René. Storia diplomatica d' Europa (1815-1868).

Roma: Editori laterza, 1978.

ALCANTÂRA, Armando (1997), La Política Científica y Tecnológica de las Universidades Públicas latino americanas Bajo condiciones de ajuste estructural: Los casos de Argentina y México. Prepared for delivery at the 1997 meeting of the Latin American Studies Association. Gadalajara, April .

ALMEIDA, Renato. A Liga das Nações: constituição, estrutura e funcionamento. Rio de janeiro: A Noite, 1938.

AMADO, Gilberto et al. Raul Fernandes: nonagésimo aniversário. Cinco retratos. Rio de Janeiro: MRE/Seção de Publicações, 1968.v 2.

l'apartheid sanitaire". Le Monde

BURNS, E. Bradford. The unwritten alliance: Rio Branco and BrazilianAmerican relations. New York: Columbia University Press, 1966.

CALÓGERAS, João Pandiá. Res nostra... São Paulo: Irmãos Ferraz, 1930. HOFFMAN, Bruce: A mano amada. História del terrorismo, Madrid, Ed. Espasa Calpe, 1999, especialmente o capítulo 7: "El terrorismo hoy y mañana".

MAISONNEUVE, Eric de La, La metamorfosis de la violencia. Ensayo sobre la guerra moderna. Buenos Aires, Grupo Editor Latinoamericano, 1998, pp 175-222. A citação é da pag. 184. 
Artigo original

Hegemonia - Revista Eletrônica de Relações Internacionais do Centro Universitário Unieuro

ISSN: $1809-1261$

UNIEURO, Brasília, número 11, 2013, pp. 4-35

PESSOA, Epitácio. Pela verdade. Rio de Janeiro: Livraria Francisco Alves Editora, 1925. .Obras completas. Corte Permanente de Justiça Internacional (1923-1930). Rio de Janeiro: INL, 1961. v. 23.

REINARES, Fernando: Terrorismo y Antiterrorismo, Ed. Paidós, Barcelona, 1998, especialmente o capítulo 5 "Terrorismo en la sociedad internacional".

SOCIEDADE DE LAS NACIONES. La obra de la sociedad de las Naciones (enero 1920-junio 1925). Ginebra Sección de Información, 1926. p.583-629 La obra de la Sociedad de las Naciones (junio 1925-octubre 1927). Ginebra: Seción de Información, 1929.

TAVARES, Ma da Conceição (1999), "Império, Território e Dinheiro". In:

Fiori,J.L: Estado e Moeda no desenvolvimento das nações. Pp 449:489. Petrópolis: Vozes.

TAYLOR, A.J.P.The Origins of the Second World War. Greenwich: Fawcett Publications, 1969.

TEMPERLEY, Harold W. Vazeille (ed.). A history of the Peace Conference of Paris. London: Oxford University Press, 1969. 6v.

ZORGBIBE, Charles, Relations Internationales - Press Universitaire de France - Paris -1999. 